\title{
Characterization of ram sperm head morphometry using the Sperm-Class Analyzer
}

\author{
A. Maroto-Morales ${ }^{\text {a }}$, M. Ramón ${ }^{\text {a,b }}$, O. García-Álvarez ${ }^{\text {b }}$, A.J. Soler ${ }^{\text {a }}$, M.C. Esteso ${ }^{\text {, }}$, \\ F. Martínez-Pastor ${ }^{\mathrm{d}}$, M.D. Pérez-Guzmán ${ }^{\mathrm{b}}$, J.J. Garde ${ }^{\mathrm{a}, \mathrm{e}, *}$ \\ ${ }^{a}$ Biology of Reproduction Group, National Wildlife Research Institute (IREC), UCLM-CSIC-JCCM, Albacete, Spain \\ ${ }^{\mathrm{b}}$ Regional Center of Animal Selection and Reproduction (CERSYRA), Valdepeñas, Spain \\ ${ }^{\mathrm{c}}$ Animal Reproduction and Obstetrics, University of León, León, Spain \\ ${ }^{\mathrm{d}}$ INDEGSAL, University of León, León, Spain \\ ${ }^{\mathrm{e}}$ Institute for Regional Development (IDR), Albacete, Spain
}

Received 6 March 2009; received in revised form 5 August 2009; accepted 9 October 2009

\section{Abstract}

Sperm morphology has been identified as a characteristic that can be useful in the prediction of fertilizing capacity. The aim of the current study was to characterize ram sperm heads morphometrically as a basis for future studies on the relationship Q2 between sperm quality and male fertility. For this purpose, ejaculates from 241 mature rams belonging to 36 different dairy herds were used to evaluate sperm head morphometry by means of the Sperm-Class Analyzer. Sperm samples, collected by Q3 artificial vagina, were diluted in PBS for the analysis. A microscope slide was prepared from single-diluted fresh sperm Q4 samples. Slides were air-dried and stained with Hemacolor. A minimum of 115 sperm heads were analyzed from each male. Each sperm head was measured for four primary parameters (area, perimeter, length, width), and four derived parameters of head shape were obtained. Significant differences in sperm head morphometry were found between rams (CV for morphometric parameters ranging from 0.9 to 10.1 ), and there were marked differences in the sperm morphometric composition of the ejaculates. For all parameters, within-animal CVs were greater than between-animal CVs. Within-animal CVs ranged from 4.2 to 10.6, showing the high degree of sperm polymorphism present in the sheep ejaculate. Significant differences in sperm head morphometry were found between rams belonging to the different herds (i.e., origin). An important part of the variability observed on morphometric parameters was due to the male itself, with an explained variance ranging Q5 from $3.6 \%$ for regularity to $34.0 \%$ for $\mathrm{p} 2 \mathrm{a}$ (perimeter ${ }^{2} / 2 \times \pi \times$ area). The explained variance by the herd of origin of the males ranged from $0.6 \%$ for regularity to $10.8 \%$ for area. Our results suggest that a genetic component might be responsible for the observed sperm head morphometry differences between herds. (C) 2009 Published by Elsevier Inc.

Keywords: Herds; Ram; SCA; Sperm head morphometry

Q1 * Corresponding author. Tel.: +34 967599200 (+2829); fax: +34 967599238 .

E-mail address: julian.garde@uclm.es (J.J. Garde).

\section{Introduction}

Significant differences have been reported in the fertility rates (number of females lambing/females inseminated) between healthy mature males [1]. The assessment of male fertility potential is very important prior to performing artificial insemination (AI) or in 
vitro fertilization (IVF) to ensure good results. To date, many studies have focused in the relationship between sperm parameters and in vivo fertility, with different outcomes [1-3].

The routine evaluation of semen, including normal sperm morphology assessment, has long been employed to evaluate the effects of freezing-thawing procedures on sperm cryosurvival. Poor semen morphology is an important indicator of decreased fertility in men [4], stallions [5], and bulls [6]. Sperm head abnormalities have been associated with early embryonic loss, lowered fertility and embryo quality [7], and reduced capacity to bind to the ovum [8]. Although normal sperm morphology may be an indicator of the fertility potential of a given male, until now correlations have been based on subjectively performed analyses. However, large variations between technicians and laboratories in the subjective evaluation of semen characteristics are known to exist [9] making accurate interpretation of the resulting data difficult.

The need for accurate objective assessment of sperm morphology has led to the development of computerQ6 assisted sperm head morphometry analysis, ASMA $[10,11]$. The precision of the ASMA system has been used to detect morphometric differences in sperm head dimensions of fertile and subfertile males [12], as well as subtle changes in head morphometry of spermatozoa from donors with elevated blood lead levels, whereas no morphologic differences were detected by manual assessment [13]. Previous studies using ASMA have also demonstrated that cryopreservation affects sperm head morphometry of bull [14], human [15], stallion [16], dog [17], and boar [18] cryopreserved spermatozoa. In these studies, sperm heads were significantly smaller in cryopreserved than in fresh-extended spermatozoa.

Sperm morphology and dimensions are extremely variable between species [19]. To date, ASMA has been applied in a number of species, including cattle $[14,20]$, goat [21], boar [22,23], horse [12,24,25], rabbit [26], red deer [27-29], and humans [30-32]. As technologies for studying the characteristics and functions of individual spermatozoa have improved, it has become clear that extensive heterogeneity of morphology exists, not only between species but also between individuals within the same species or breed [33]. Thus, betweenmale variation in sperm morphology has been recorded for several species [17,34-36]. To our knowledge, little attention has been paid to the study of sperm morphometry in sheep using ASMA. To date, there have been only two studies describing the use of ASMA in the ram $[37,38]$, and no information is available about the morphometric characterization of fresh ram spermatozoa. Previous work [37] has morphometrically characterized the frozen-thawed spermatozoa of this species. Furthermore, efforts to evaluate the effects of different fixative techniques on ram sperm head morphometry have also been reported [38]. However, these two studies used a rather small number of animals (i.e., 10 and 5 rams, respectively).

The Manchega sheep is an autochthonous dairy Q7 103 breed from Spain, which includes a white and a black variety. The white Manchega sheep variety is one of the most important Spanish dairy breeds, widely distributed in the central area of Spain [39]. Their fertility after artificial insemination (AI) at an induced estrous cycle has been shown to range from a mean value of $40 \%$ with cervical inseminations and refrigerated semen [40] to a mean value of $60 \%$ after laparoscopic intrauterine inseminations and frozen-thawed semen [41]. In the Manchega sheep breed, males have not yet been genetically selected for fertility, therefore different males selected for particular traits such as milk production are expected to exhibit considerable diversity if sperm characteristics are inherited traits.

Considering this background, the initial purpose of the current study was to investigate the morphometric characteristics of sheep sperm heads using ASMA as a basis for future studies on the relationship between sperm quality and male fertility. A further aim was to explore the variation in sperm head morphometry between individual males and that between rams belonging to different herds (i.e., origin).

\section{Materials and methods}

All chemicals were of reagent grade and were purchased from Sigma or Merck (both of Madrid, Spain).

\subsection{Study population}

Animal manipulations were performed in accordance with the Spanish Animal Protection Regulation RD1201/2005, which conforms to European Union Regulation 2003/65. Adult rams were maintained and managed at the Regional Centre of Animal Selection and Reproduction (CERSYRA) located in Valdepeñas, Ciudad Real, Spain.

Computer-assisted sperm head morphometry analysis was performed on fresh semen of $241 \mathrm{rams}$ of the Manchega sheep breed belonging to 36 herds of origin. Ram calves were purchased based on their expected genetic value. At approximately 3 to 4 mo of age, these 
rams were transferred from the different herds to the AI center (CERSYRA), where, after quarantine and training periods of 4 mo, semen was collected. Thus, all males were maintained under the same environmental conditions since they were 3 to 4 mo old. When these rams passed a strict semen-quality test (two consecutive ejaculates collected within a 3- or 4-d interval $>0.7 \mathrm{~mL}$, containing $>3000 \times 10^{6}$ spermato$\mathrm{zoa} / \mathrm{mL}$, with $>75 \%$ motility, $>90 \%$ normal morphology, and $>75 \%$ intact acrosomes), they started to be used for AI purposes. The fertility of these animals was $42.6 \pm 19.4 \%$ (mean $\pm \mathrm{SD}$ ), ranging from $8.0 \%$ to $90.0 \%$. Considering the herd of origin, the average fertility of the herds was $41.5 \pm 10.6 \%$, ranging from $18.2 \%$ to $75.0 \%$.

All semen samples were collected by means of an artificial vagina during 2005 and 2006. Regular collection (i.e., twice a week) from the examined males was performed in the weeks preceding this study. Semen volume, sperm concentration, and subjective scores of motility (wave motion) were assessed shortly after collection. Volume of each ejaculate was directly measured in graduated tubes. Concentration was estimated using a hemocytometer. Wave motion was scored from 1 to 5 on a wet mount of neat semen at $\times 100$ magnification (values ranged from 0 [no movement] to 5 [strong wave movement]). Also, within 8 8 this interval, aliquots were diluted in PBS with bovine serum albumin $(5 \mathrm{mg} / \mathrm{mL})$ and used to assess individual sperm motility (0 to 100\%). Only ejaculates with values of wave motion and individual sperm motility $>3$ and $80 \%$, respectively, were used.

\subsection{Morphometric analysis of sperm heads}

Microscope slides were prepared from each diluted sample (upon dilution in PBS) by placing $5 \mu \mathrm{L}$ of the sperm samples on the clear end of a frosted slide and dragging the drop across the slide. Semen smears were air-dried and stained using a Hemacolor (Merck) procedure, originally described for staining of ram [38], alpaca [34], and red deer [27-29] sperm heads. Stained sperm samples were permanently mounted to the slide with a coverslip and dibutyl phthalate xylene (DPX).

Stained slides were used to perform ASMA using the morphometry module of a commercially available system (Sperm-Class Analyser [SCA]; Microptic, Barcelona, Spain). The machine was equipped with a Labophot-2 (Nikon, Tokyo, Japan) microscope with a $\times 40$ bright-field objective and a video camera (CCD AVC-D7CE; Sony Corporation, Tokyo, Japan) con- nected to a Pentium $950 \mathrm{MHz}$ processor. The illumination source was centered, and the intensity of the bulb and the gain and offset of the camera were standardized for all samples. The configuration of the computer system included a PIP-1024 B video digitizer board (Matrox Electronic Systems Ltd, Quebec, Canada), the sperm image analysis software, and a high-resolution assistant monitor (Sony Trinitron PVM-1443MD; Sony Corporation). The array size of the video frame recorder was $512 \times 512 \times 8$ bits, digitized images were made up of 262,144 pixels (picture elements) and 256 gray Q9 203 levels. Resolution of images was 0.15 and $0.11 \mu \mathrm{m}$ per pixel in the horizontal and vertical axes, respectively.

The morphometric dimensions for head area (A; $\left.\mu \mathrm{m}^{2}\right)$, head perimeter $(\mathrm{P} ; \mu \mathrm{m})$, head length $(\mathrm{L} ; \mu \mathrm{m})$, head width $(\mathrm{W} ; \mu \mathrm{m})$, and four derived parameters of head shape-ellipticity (L/W), p2a $\left(\mathrm{P}^{2} / 4 \pi \mathrm{A}\right)$, elonga- 21020 head shape-ellpticity (L/W), p2a ( tion $([\mathrm{L}-\mathrm{W}] /[\mathrm{L}+\mathrm{W}])$, and regularity $(\pi \mathrm{LW} / 4 \mathrm{~A})-210$ were acquired for 120 to 125 images ensuring a 211 minimum of 115 properly measured sperm heads after 212 improperly measured sperm heads were removed from 213 the analysis. The shape feature $\mathrm{p} 2 \mathrm{a}$ compares the perimeter of an object to its area [42]. This parameter takes a minimum value of 1 for a circle, increasing when the shape differs from it. The measurements of each individual sperm head from each ejaculate were saved in an Excel (Microsoft Corporation, Redmond, WA, USA) compatible database by the software for further $\mathbf{Q 1 1} 220$ analysis.

\subsection{Statistical analysis}

All statistical analyses were carried out using the $\mathrm{R}$

(R Development Core Team, 2008) statistical environ- Q12 224 ment. Where applicable, $\mathrm{P}<0.05$ was considered as 225 statistically significant unless otherwise stated.

Previous to statistical analysis, the assumption of normality was checked out using graphical methods and Kolmogorov-Smirnov normality test, and a study to remove outlier values was carried out.

For each morphometric parameter, the mean, the minimum and maximum values, the standard deviation, and skewness and kurtosis were calculated.

Moreover, the variability of each parameter at different grouping levels was calculated using coefficients of variation (CVs). Coefficients of variation were calculated as the standard deviation divided by the mean times 100 (for expressing it as a percentage). Previously, we determined the variability of the slide within ejaculate and the variability of the ejaculate within male in order to test if the variability due to the slide preparation or to different ejaculates would be high

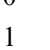

\section{(1)} 24 
Table 1

Morphometric characterization of fresh ram sperm heads.*

\begin{tabular}{|c|c|c|c|c|c|}
\hline \multirow[t]{2}{*}{ Sperm parameter } & \multicolumn{5}{|c|}{ Statistics } \\
\hline & Mean & Range & SD & Skewness & Kurtosis \\
\hline Length, $\mu \mathrm{m}$ & 8.90 & $6.02-10.87$ & 0.49 & 0.02 & 0.09 \\
\hline Width, $\mu \mathrm{m}$ & 4.79 & $2.42-7.81$ & 0.33 & 0.39 & 1.54 \\
\hline Area, $\mu \mathrm{m}^{2}$ & 35.02 & $19.04-53.35$ & 3.17 & 0.45 & 1.09 \\
\hline Perimeter, $\mu \mathrm{m}$ & 26.80 & $20.74-40.77$ & 2.16 & 0.79 & 1.03 \\
\hline $\mathrm{p} 2 \mathrm{a}$ & 1.65 & $1.21-3.92$ & 0.25 & 1.44 & 4.91 \\
\hline Ellipticity & 1.86 & $0.77-3.42$ & 0.13 & 0.39 & 1.75 \\
\hline Elongation & 0.30 & $0.09-0.55$ & 0.03 & 0.01 & 0.66 \\
\hline Regularity & 0.96 & $0.78-1.22$ & 0.04 & 0.21 & 0.27 \\
\hline
\end{tabular}

*Data were obtained from single ejaculates $(\mathrm{n}=27,963)$ collected from 241 rams. Values of mean, range, and SD are given in $\mu \mathrm{m}($ length, width, and perimeter) and $\mu \mathrm{m}^{2}$ (area), whereas shape factors are dimensionless.

enough to hinder the rest of the analyses. Thus, we obtained semen samples from 10 males collected on the same day and processed to obtain three slides per male, calculating the $\mathrm{CVs}$ between slides $\left(\mathrm{CV}_{\text {slide }}\right)$. In a second trial, we obtained semen samples from 10 males collected on three different days, calculating the coefficients of variation between ejaculates $\left(\mathrm{CV}_{\text {ejaculate }}\right)$. We decided that an acceptable $\mathrm{CV}$ value should not be higher than $5 \%$, which we tested using a one-sample $t$ test with the alternative hypothesis being that the CV had a lower mean than $5 \%$.

Then, we studied the within-animal and betweenanimal variation to establish the best parameters to differentiate among males on the basis of their sperm morphometric parameters, calculating the coefficients of variation within animal $\left(\mathrm{CV}_{\text {within }}\right)$ and between animals $\left(\mathrm{CV}_{\text {between }}\right)$.

A regression analysis to evaluate the effect of male and of herd (i.e., origin) on morphometric variability was carried out. The model used in that analysis was the following:

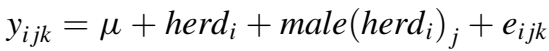

where $y_{i j k}$ is the value of the morphometric parameter (length, width, area, perimeter, ellipticity, p2a, elongation, and regularity; 27,963 observations), $\mu$ is the global mean of the morphometric parameter, herd $_{i}$ is the fixed effect herd of origin (36 levels), male $\left(\text { herd }_{i}\right)_{j}$ is effect of male $j$ from herd of origin $i$, and $e_{i j k}$ is the error.

The explained variance and $\mathrm{P}$ value of each morphometric parameter was recorded. Explained variance was defined as the percentage of variance from the total variance that is explained for the effects on study.

To compare the variability among different morphometric parameters, a normalization of data was carried out. Thereby, for each morphometric parameter on each male individual, measures were divided by the mean value of this parameter. After that transformation, all morphometric characteristics will present the same average value, which will be equal to 1 , remaining its own variability.

\section{Results}

Descriptive statistics of the whole sperm population were calculated to characterize Manchega ram spermatozoa. A total of 27,963 property digitized sperm heads belonging to 241 males were analyzed. Results are summarized in Table 1. The values for all measures of sperm head dimensions were determined to be normally distributed by Kolmogorov-Smirnov normality test (results not shown). Area and p2a showed a large degree of variation between individuals (ranges, 19.0 to $53.3{\mu \mathrm{m}^{2}}^{2}$ and 1.2 to 3.9 , respectively). However, length and regularity were consistently maintained between rams (ranges, 6.0 to 10.9 and 0.8 to 1.2 , respectively). Q13295

The analyses of between-slide (within ejaculate) and between-ejaculate (within male) variability showed that the primary parameters rendered $\mathrm{CV}$ values below $5 \%$ $(\mathrm{P}<0.001)$. Therefore, we considered that the variability associated with these factors should not interfere with the rest of the variability study. Average values are shown in Table 2.

Table 2

Means of between-slide (within-ejaculate) and between-ejaculate (within-male) $\mathrm{CVs}(\%)$ for the primary morphometric parameters.*

\begin{tabular}{lllll}
\hline & $\mathrm{CV}, \%$ & & & \\
\cline { 2 - 5 } & Length & Width & Area & Perimeter \\
\hline Between-slide & 0.99 & 0.92 & 1.61 & 2.61 \\
Between-ejaculate & 1.14 & 1.29 & 1.74 & 3.00
\end{tabular}

*In all cases, $\mathrm{CVs}$ were significantly below $5 \%(\mathrm{P}<0.001)$. 
Table 3

Means of within-male and between-male CVs.

\begin{tabular}{lllllllll}
\hline & $\mathrm{CV}, \%$ & & & & & \\
\cline { 2 - 8 } & Length & Width & Area & Perimeter & p2a & Ellipticity & Elongation & Regularity \\
\hline Within-male & 4.84 & 5.26 & 6.47 & 6.11 & 10.64 & 6.30 & 9.48 & 4.25 \\
Between-male & 2.59 & 4.19 & 5.92 & 5.13 & 10.10 & 3.11 & 4.69 & 0.91 \\
\hline
\end{tabular}

Within-animal CVs ranged from $4.84 \%$ (length) to $10.64 \%$ (p2a). Between-animal CVs were lower, ranging from $0.91 \%$ (regularity) to $10.10 \%$ (p2a) (Table 3).

Mean values and standard errors for morphometric parameters of the 241 studied rams are represented in Fig. 1. Statistical analysis of morphometric parameters showed differences $(\mathrm{P}<0.001)$ between males for all the parameters under consideration. To definitively assess if sperm head dimensions were similarly variable between rams, we normalized the values for all sperm morphometric parameters (Fig. 2). The use of normalized values rather than absolute values (Fig. 1) allows for direct comparison between sperm head dimensions that differ in units of measure (Fig. 1). The normalized data showed that in general terms, p2a, area, and elongation were the most variable sperm head parameters between rams, with the opposite being true for regularity (Fig. 2).

In the regression analysis, the herd of origin and male effects were considered together. Both effects were significant (Table $4 ; \mathrm{P}<0.001$ ). Variance explained by herd of origin ranged from $0.59 \%$ (regularity) to $10.85 \%$ (area). For the male effect, explained variance ranged from $3.58 \%$ (regularity) to $34.01 \%$ (p2a). The variability observed on morphometric data for each herd of origin is shown in Fig. 3. We found significant differences $(\mathrm{P}<0.001)$ between herds for all sperm head morphometric parameters.

\section{Discussion}

Subjective evaluation of sperm morphology often lacks replication, and the corresponding CVs are very high [9]. This fact has led to the development of ASMA systems designed for human semen $[10,11]$. The introduction of ASMA has allowed rapid, accurate, and reproducible evaluation, providing an objective basis from which to study sperm morphology $[4,5,11,37]$. It is now simple to collect a large data set composed of thousands of individual sperm parameters in a relative short time.

In the current study, more than 27,900 spermatozoa representing 241 mature Manchega males were analyzed in an attempt to quantify the morphometric dimensions and the shape of sperm head from rams. The large sample of mean sperm head dimensions from 36 herds of rams (Fig. 1) followed normal distributions without skew or kurtosis. Thus, there was significant between-ram variation in sperm head morphometric parameters, but the overall population pattern followed a normal distribution.

The range of values for sperm head dimensions for all 241 rams in the current study were similar to those previously reported [38]. However, in thawed spermatozoa from 10 rams, head area ranged from $\sim 28$ to $\sim 29 \mu \mathrm{m}^{2}$ [37], whereas an average of $35 \mu \mathrm{m}^{2}$ was observed in our study. We prepared the smears for ASMA from freshly diluted semen samples, fixed in methanol and stained with Hemacolor. The differences found between the results reported in the previous study and those in the current work could be due to differences in the fixation procedure [38], in the staining technique [43], or in the kind of semen (fresh vs. thawed) [1518,28]. It has been reported that sperm heads were significantly smaller in cryopreserved spermatozoa than in fresh-extended spermatozoa [15-18,28]. Sperm morphology and dimensions are extremely variable between (sometimes close) species [19,44]. Although selective breeding has shown to result in significant differences in sperm morphometry between breeds within a species, there is still significant variance between individual males within a breed [19]. Thus, our study has revealed that there is a considerable variation in sperm head dimensions between individual males within a sheep breed (Manchega). Besides, our results have demonstrated that there are significant differences in sperm head morphometry between rams belonging to different herds (origin). Although we cannot explain why these variations exist, our results, taken together, support the hypothesis for genetic control of sperm phenotype.

Our finding that there are differences between spermatozoa from healthy rams is potentially as important as it has been the case for stallions [36], canine [17], alpaca [34], and monkey [35]. This finding suggests that the former concept of normality requires some reconsideration, with the introduction of new 

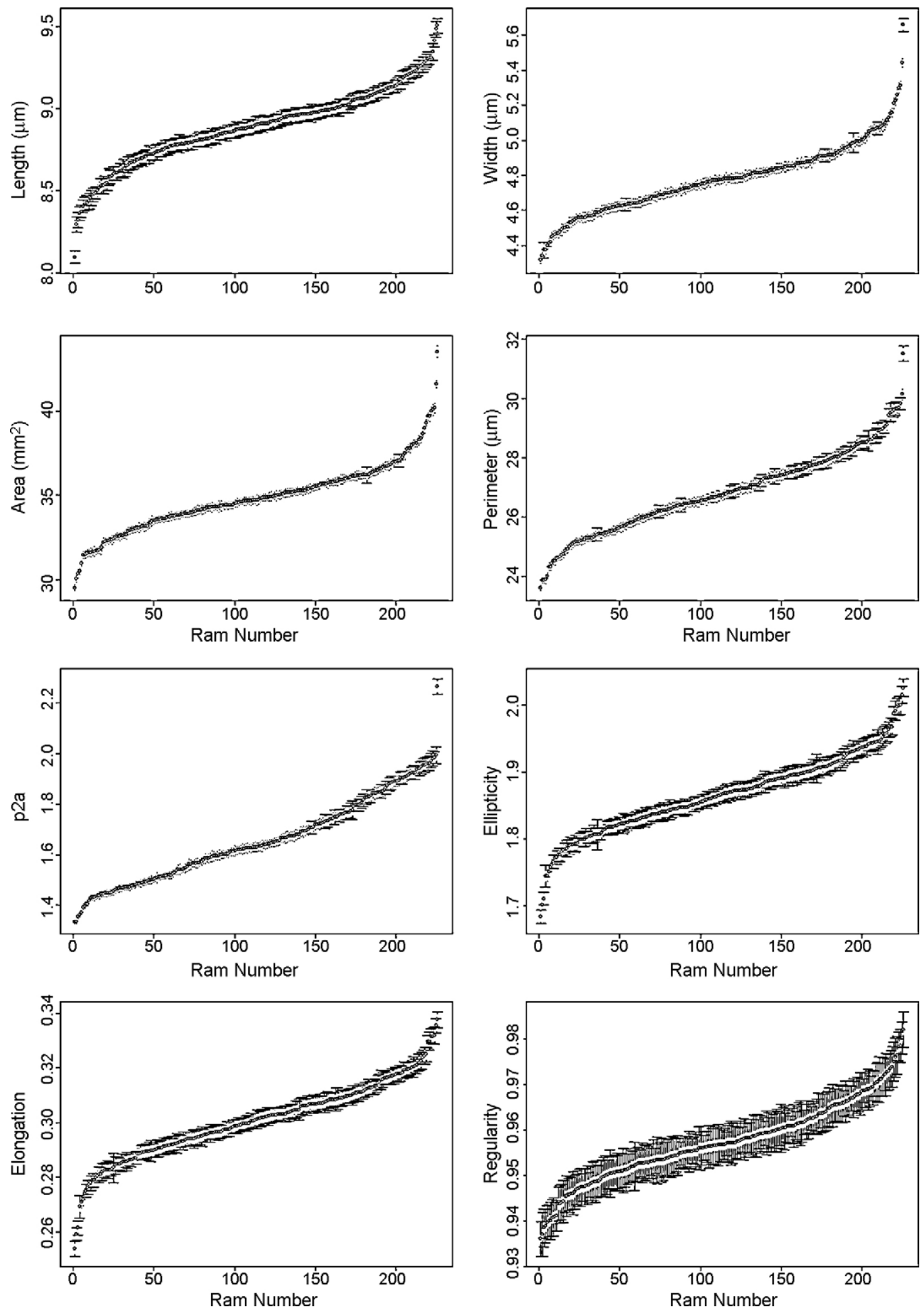

Fig. 1. Differences in sperm head morphometric values between animals (Animals 1 to 241). Circles represent the mean values and whiskers the standard error for the spermatozoa analyzed within each ram. Significant differences between rams were found for all parameters $(\mathrm{P}<0.001)$. 

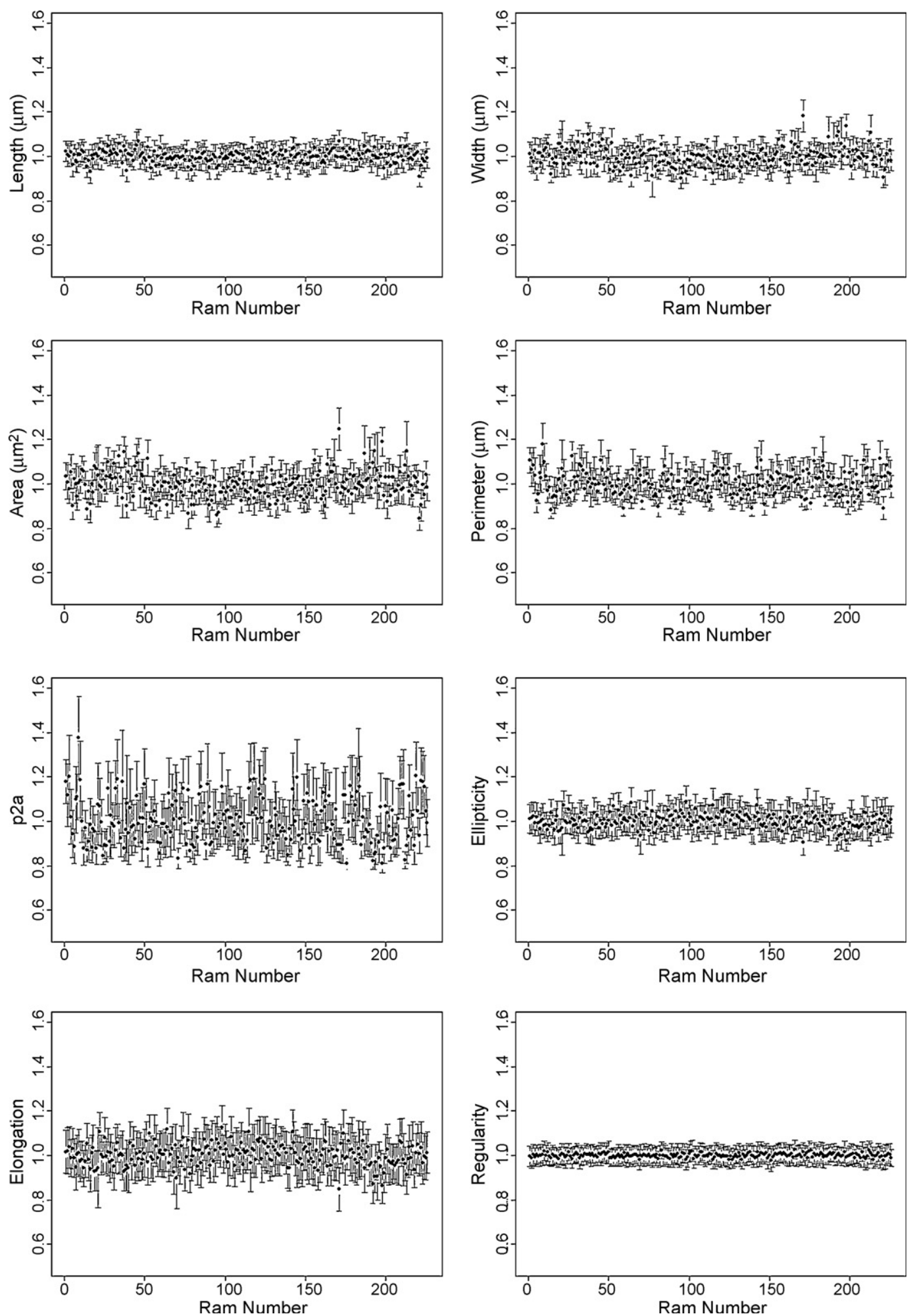

Fig. 2. Differences in sperm head morphometric normalized values from males (Animals 1 to 241). Circles represent the mean values and whiskers the standard error for the spermatozoa analyzed within each ram. Significant differences between rams were found for all parameters $(\mathrm{P}<0.001)$. 
Table 4

Explained variance and $\mathrm{P}$ values for herd of origin of males and male effects on sperm head morphometry.

\begin{tabular}{llrl}
\hline $\begin{array}{l}\text { Sperm } \\
\text { parameter }\end{array}$ & Statistics & \\
\cline { 2 - 4 } & & $\begin{array}{c}\text { Explained } \\
\text { variance, } \%\end{array}$ & P value \\
\hline Length & Herd of origin & 4.99 & 0.001 \\
& Male & 16.18 & 0.001 \\
Width & Herd of origin & 9.57 & 0.001 \\
& Male & 27.05 & 0.001 \\
Area & Herd of origin & 10.85 & 0.001 \\
& Male & 31.31 & 0.001 \\
Perimeter & Herd of origin & 7.22 & 0.001 \\
& Male & 30.25 & 0.001 \\
p2a & Herd of origin & 7.98 & 0.001 \\
& Male & 34.01 & 0.001 \\
Ellipticity & Herd of origin & 4.64 & 0.001 \\
& Male & 14.39 & 0.001 \\
Elongation & Herd of origin & 4.72 & 0.001 \\
& Male & 14.55 & 0.001 \\
Regularity & Herd of origin & 0.59 & 0.001 \\
& Male & 3.58 & 0.001 \\
\hline
\end{tabular}

criteria for the definition of what should be considered a normal spermatozoa. For example, in the ram, where more than $90 \%$ of the sperm cells are subjectively considered normal when they are visually evaluated, we have found significant differences between animals for most of the morphometric parameters studied. Given the inherent variability of subjective visual analysis [9], it is doubtful that such differences could be detected without the use of ASMA. It is not reasonable to ignore this fact in characterizing the reproductive quality of males, considering that some studies have pointed out that morphometric values of sperm cells are related to fertility in human [45], stallions [12], boars [22], and bulls [14]. The between-male variance in sperm head dimensions and shape recorded in our study may have important impact on the hydrodynamics and swimming velocity of the sperm cell of this species, as originally has been suggested [33], and also provides valuable potential to develop new experiments on the relationship between sperm head dimensions and in vivo fertility in rams, which we are currently undertaking.

These differences in sperm morphometry between males have been widely reported, but our understanding of the causal factors that generate such differences is still poor. Genetically determined variation in sperm morphology has been recognized for some time and was demonstrated clearly in the observation of phenotypic differences between sperm of different strains of mice [46]. It has been suggested that variation in sperm morphology is originated during spermatogenesis when genotypic effects influence sperm structure $[47,48]$. Sperm phenotype appears to be controlled by genes transcribed in the premeiotic phase of development (diploid genome) [19]. Clear examples of sperm development and morphology under strict genetic control have been demonstrated in studies linking inbreeding coefficients and poor ejaculate quality [48]. Therefore, it is reasonable to assume that the betweenmale differences reported here were under genetic control.

Because males included in this work have a diverse origin (herd), we studied if differences observed for morphometric parameters between males could be due to that origin. Given that, in this sample of males belonging to 36 populations (the environmental factors were common to all individuals as they were 3 to 4 mo old), the effect of the herd of origin on sperm morphometry suggests a genetic effect. The combination of an individual and herd effects builds strong support for the view that variation in ram sperm head morphometry exists and may be genetically inherited.

In some species, variability of sperm head morphometry shows low values within animals and relatively high values between animals, indicating a high constancy of sperm morphometric parameters of an individual and making it possible to differentiate between individuals using CV $[38,49]$. In our study, CVs within animals were higher than those observed between animals for all parameters, thus showing the high degree of sperm polymorphism present in the Manchega sheep ejaculates. Similar results have been reported in dog [50], horse [12], and alpaca ejaculates [34]. Contrarily, previous work carried out with five Merino rams reported that within-animal CVs were lower than the between-animal CVs [38]. The differences found between the results reported in the previous study [38] and those in the current work could be due to the use of different criteria to select the rams. The animals used in the previous work were considered to be fertile on the basis of their use for AI [38]. In our study, rams were not preselected for fertility or for sperm characteristics. The fertility of the studied animals was $42.6 \pm 19.4 \%$, ranging from $8.0 \%$ to $90.0 \%$. Probably, if male selection had been carried out for fertility, we would expect to observe a less profound variation in sperm phenotype (such as morphometry) within a male. This did not happen in our study because we selected males for particular traits such as milk production, exhibiting a great diversity in sperm size and shape within each male.

In some species, it was possible to differentiate between individuals using $\mathrm{CVs}$ within and between 

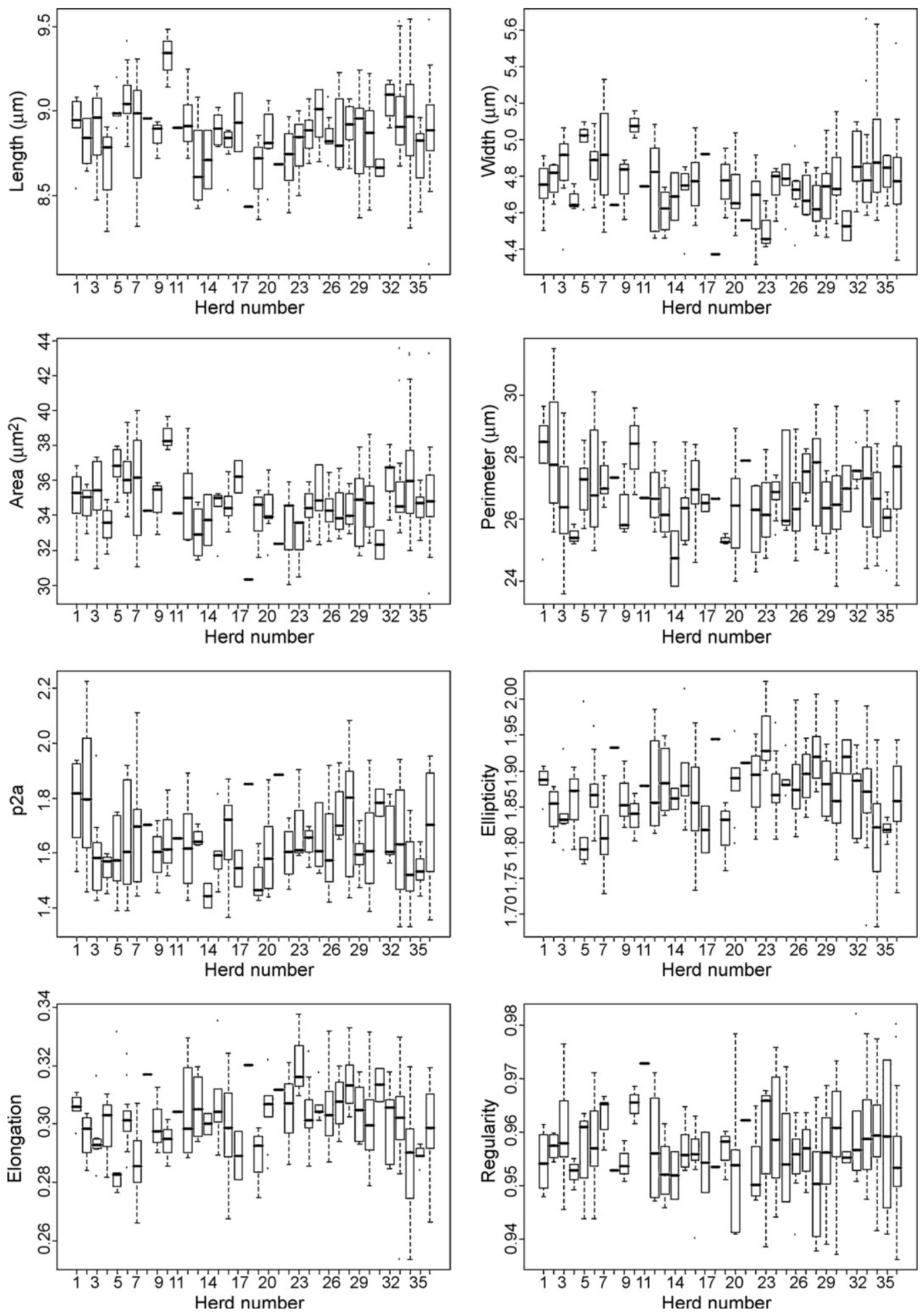

Fig. 3. Box-and-whisker plots showing variations in sperm head morphometric values from herds of origin (Herds 1 to 36 ). Each box encloses the 25th and 75th percentiles, the horizontal line within the box is the median value, and the whiskers extend to the 5th and 95th percentiles. Significant differences between herds of origin were found for all parameters $(\mathrm{P}<0.001)$. 
animals [35]. The most suitable parameters for use in the identification of individual males are those characterized by relatively low within-animal and relatively high between-animal CVs, respectively. In the particular case of the ram, the within-animal CVs suggest that different sperm subpopulations coexist in ram ejaculates. The ASMA technology and multivariate cluster analyses have been used to define sperm morphologic subpopulations in boars [47,51], stallions [25], stags [27,52], and bulls [53]. This new opportunity to analyze small but significant differences between apparently normal spermatozoa is particularly interesting because the existence of subpopulations of "normal" spermatozoa presenting different fertility profiles in the same sample has been reported [25]. Semen analyses should therefore be performed to establish the presence of each of these subpopulations, not just to provide average values for the semen population as a whole [47,51,52,54]. Besides, different authors have pointed out the relation between sperm head morphometry and reproductive performance [12,42] and between semen cryopreservation and relative percentage of sperm head morphometric subpopulations [51,52,54]. Future work will use ASMA to identify sperm morphometric subpopulations in fresh ram ejaculates and their possible relationships with fertility and freezability.

In summary, the results of the current study showed that significant differences can be found between healthy rams concerning the sperm head morphometry. Besides, significant differences were detected in the sperm head morphometry between rams belonging to different herds (origin). Given that in this sample of males belonging to 36 populations, the environmental factors were common to all individuals since they were 3 to 4 mo old, the effect of the herd of origin on sperm morphometry supports the hypothesis for a genetic control of this sperm trait. In the particular case of this study, the within-ram CVs suggest that different sperm subpopulations coexist in ram ejaculates. Now that the sperm head dimensions and shape for the fresh ram spermatozoa have been characterized, it will be interesting to analyze whether the morphometric definition of a ram ejaculate can anticipate its fertilizing ability. In this sense, our group is carrying out further experiments to evaluate the relationship between sperm head morphometry and in vivo fertility in rams. Similarly, we are currently interested in identifying sperm morphometric subpopulations in fresh ram ejaculates and their possible relationships with fertility and freezability.

\section{Acknowledgments}

This work was supported by the Education and Science Council of Junta de Comunidades de CastillaLa Mancha (PBC-05-008). A. Maroto-Morales and O. García-Álvarez were recipients of scholarships from Junta de Comunidades de Castilla-La Mancha and INIA, respectively. M.C. Esteso was supported by the Juan de la Cierva program, and F. Martínez-Pastor was supported by the Ramón y Cajal program (Spanish Ministry of Science and Innovation).

\section{References}

[1] Rodriguez-Martínez H. Can we increase the estimative value of semen assessment? Reprod Domest Anim 2006;41:2-10.

[2] Rodríguez-Martínez H. State of art in farm animal sperm evaluation. Reprod Fertil Dev 2007;19:91-101.

[3] Rodríguez-Martínez H, Barth AD. In vitro evaluation of sperm quality related to in vivo function and fertility. Soc Reprod Fertil 2007;64:34-59.

[4] Kruger TF, DuToit TC, Franken DR, Acosta AA, Oehniger SC, Menkveld R, Lombard CJ. A new computeterized method of reading sperm morphology (strict criteria) is as efficient as technician reading. Fertil Steril 1993;59:202-9.

[5] Jasko DJ, Lein DH, Foote RH. Determination of the relationship between sperm morphologic classifications and fertility in stallions: 66 cases (1987-1988). J Am Vet Med Assoc 1990;197:389-94.

[6] Sekoni VO, Gustafsson BK. Seasonal variations in the incidence of sperm morphological abnormalities in dairy bulls regularly used for artificial insemination. Br Vet J 1987;143:312-7.

[7] DeJarnette JM, Saacke RG, Bame J, Vogler CJ. Accessory sperm: their importance to fertility and embryo quality, and attempts to alter their numbers in artificially inseminated cattle. $\mathrm{J}$ Anim Sci 1992;70:484-91.

[8] Kot MC, Handel MA. Binding of morphologically abnormal sperm to mouse egg zonae pellucidae in vitro. Gamete Res 1987;18:57-66.

[9] Saacke RG. Components of semen quality. Anim Sci 1982;55:113.

[10] Katz DF, Overstreet JW, Samuels SJ, Niswander PW, Bloom TD, Lewis EL. Morphometric analysis of spermatozoa in the assessment of human male fertility. J Androl 1986;7:203-10.

[11] Pérez-Sánchez F, de Moserrat JJ, Soler C. Morphometric analysis of human sperm morphology. Int J Androl 1994;17:248-55.

[12] Casey PJ, Gravance CG, Davis RO, Chabot DD, Liu IKM. Morphometric differences in sperm head dimensions of fertile and subfertile stallions. Theriogenology 1997;47:575-82.

[13] Davis RO, Gravance CG, Osario AM. Sperm morphology abnormalities among lead-exposed battery plant workers [abstract]. Fertil Steril 1993;60:56s

[14] Gravance CG, Vishwanath R, Pitt C, Garner DL, Casey PJ. Effects of cryopreservation on bull sperm head morphometry. J Androl 1998;19:704-9.

[15] Thompson LA, Brook PF, Warren MA, Barratt CL, Cooke ID. A morphometric comparison of the nuclear morphology of fresh and frozen-thawed human zona-bound and unbound sperm. J Androl 1994;15:337-42. 
[16] Arruda RP, Ball BA, Gravance CG, Garcia AR, Liu IKM. Effects of extenders and cryoprotectants on stallion sperm head morphometry [abstract]. Theriogenology 2002;58:253-6.

[17] Rijsselaere T, Van Soom A, Hoflack G, Maes D, de Kruif A. Automated sperm morphometry and morphology analysis of canine semen by the Hamilton-Thorne analyser. Theriogenology 2004;62:1292-306.

[18] García-Herreros M, Baron FJ, Aparicio IM, Santos AJ, GarciaMarin LJ, Gil MC. Morphometric changes in boar spermatozoa induced by cryopreservation. Int J Androl 2008;31:490-8.

[19] Morrow EH, Gage MJG. Consistent significant variation between indiviudal males in spermatozoal morphometry. J Zool Lond 2001;254:147-53.

[20] Gravance CG, Vishwanath R, Pitt C, Casey PJ. Compueter automated morphometric analysis of bull sperm heads. Theriogenology 1996;46:1205-15.

[21] Gravance CG, Lewis KM, Casey PJ. Computer automated sperm head morphometry analysis (ASMA) of goat spermatozoa. Theriogenology 1995;44:989-1002.

[22] Hirai M, Boersma A, Hoeflich A, Wolf E, Foll J, Aumüller TR, Braun J. Objectively measured sperm motility and sperm head morphometry in boars (Sus scrofa): relation to fertility and seminal plasma growth factors. J Androl 2001;22:104-10.

[23] García-Herreros M, Aparicio IM, Barón FJ, García-Marín LJ, Gil MC. Standardization of sample preparation, staining and sampling methods for automated sperm head morphometry analysis of boar spermatozoa. Int J Androl 2006;29:553-63.

[24] Ball BA, Mohammed HO. Morphometry of stallion spermatozoa by computer-assisted image analysis. Theriogenology 1995;44: 367-377.

[25] Gravance CG, Liu IK, Davis RO, Hughes JP, Casey PJ. Quantification of normal head morphometry of stallion spermatozoa. J Reprod Fertil 1996;108:41-6.

[26] Gravance CG, Davis RO. Automated sperm morphometry analysis (ASMA) in the rabbit. J Androl 1995;16:88-93.

[27] Esteso MC, Fernández-Santos MR, Soler AJ, Garde JJ. Head dimensions of cryopreserved red deer spermatozoa are affected by thawing procedure. Cryo Letters 2003;24:261-8.

[28] Esteso MC, Fernández-Santos MR, Soler AJ, Montoro V, Quintero-Moreno A, Garde JJ. The effects of cryopreservation on the morphometric dimensions of Iberian red deer (Cervus elaphus hispanicus) epididymal sperm heads. Reprod Domest Anim 2006;41:241-6.

[29] Esteso MC, Soler AJ, Fernández-Santos MR, Quintero-Moreno A, Garde JJ. Functional significance of the sperm head morphometric size and shape for determining freezability in iberian red deer (Cervus elaphus hispanicus) epididymal sperm samples. J Androl 2006;27:662-70.

[30] Davis RO, Gravance CG. Standardization of specimen preparation, staining, and sampling methods improves automated sperm head morphometry analysis. Fertil Steril 1993;59:412-7.

[31] Kruger TF, du Toit TC, Franken DR, Menkveld R, Lombard CJ. Sperm morphology: assessing the agreement between the manual method (strict criteria) and the sperm morphology analyzer IVOS. Fertil Steril 1995;63:134-41.

[32] Kruger TF, Lacquet FA, Sarmiento CA, Menkveld R, Ozgür K, Lombard CJ, Franken DR. A prospective study on the predictive value of normal sperm morphology as evaluated by computer (IVOS). Fertil Steril 1996;66:285-91.

[33] Malo AF, Gomendio M, Garde J, Lang-Lenton B, Soler AJ, Roldan ER. Sperm desing and sperm function. Biol Lett 2006; 22:2. 246-249.
[34] Buendía P, Soler C, Paolicchi F, Gago G, Urquieta B, PérezSánchez F, Bustos-Obregón E. Morphometric characterization and classification of alpaca sperm heads using the Sperm-Class Analyzer® computer-assisted system. Theriogenology 2002; 57:1207-18.

[35] Gago C, Pérez-Sánchez F, Yeung CH, Tablado L, Cooper TG, Soler C. Morphological characterization of ejaculated Cynomolgus monkey (Macaca fascicularis) sperm. Am J Primatol 1999;47:105-15.

[36] Hidalgo M, Rodríguez I, Dorado J, Soler C. Morphometric classification of Spanish thoroughbred stallion sperm heads. Anim Reprod Sci 2008;103:374-8.

[37] Gravance CG, Champion ZJ, Casey PJ. Computer-assisted sperm head morphometry analysis (ASMA) of cryopreserved ram spermatozoa. Theriogenology 1998;49:1219-30.

[38] Sancho M, Pérez-Sánchez F, Tablado L, de Monserrat JJ, Soler C. Computer assisted morphometric analysis of ram sperm heads: evaluation of different fixative techniques. Theriogenology 1998;50:27-37.

[39] Calvo JH, Bouzada JA, Jurado JJ, Serrano M. Genetic substructure of the Spanish Manchega sheep breed. Small Rumin Res 2006;64:116-25.

[40] Gómez-Brunet A, Santiago-Moreno J, Montoro V, Garde J, Pons P, Gonzaléz-Bulnes A, López-Sebastián A. Reproductive performance and progesterone secretion in estrus-induced Manchega ewes treated with hCG at the time of AI. Small Rumin Res 2007;71:117-22.

[41] Gutiérrez-Adán A, Pérez-Garnelo, Granados J, Garde JJ, PérezGuzmán MD, Pintado B, De la Fuente J. Relationship between sex ratio and time of insemination according to both time of ovulation and maturational stage of oocyte. Zygote 1999;7:3743.

[42] Sailer BL, Jost LK, Evenson DP. Bull sperm head morphometry related to abnormal chromatin structure and fertility. Cytometry 1996;24:167-73.

[43] Boersma AA, Braun J, Stolla R. Influence of random factors and two different staining procedures on computer assisted sperm head morphometry in bulls. Reprod Domest Anim 1999;34:7782.

[44] Cassinello J, Abaigar T, Gomendio M, Roldan ER. Characteristics of the semen of three endangered species of gazelles (Gazella dama mhorr, G. dorcas neglecta and G. cuvieri). J Reprod Fertil 1998;113:35-45.

[45] Ombelet W, Menkveld R, Kruger TF, Steeno O. Sperm morphology assessment: historical review in relation to fertility. Hum Reprod Update 1995;1:543-57.

[46] Beatty RA, Sharma KN. Genetic of gametes II. Strain differences in spermatozoa from 8 inbred strains of mice. Proc R Soc Biol Sci 1960;68:25-53.

[47] Thurston LM, Watson PF, Mileham AJ, Holt WV. Morphologically distinct sperm subpopulations defined by Fourier shape descriptors in fresh ejaculates correlate with variation in boar semen quality following cryopreservation. J Androl 2001;22: 382-394.

[48] Roldan ER, Cassinello J, Abaigar T, Gomendio M. Inbreeding, fluctuating asymmetry, and ejaculate quality in an endangered ungulate. Proc Biol Sci 1998;265:243-8.

[49] Alvarez M, García-Macías V, Martínez-Pasto F, Martínez F, Borragán S, Mata M, et al. Effects of cryopreservation on head morphometry and its relation with chromatin status in brown bear (Ursus arctos) spermatozoa. Theriogenology 2008;70: 1498-1506. 
[50] Nuñez-Martinez I, Moran JM, Pena FJ. Do computer-assisted, morphometric-derived sperm characteristics reflect DNA status in canine spermatozoa? Reprod Domest Anim 2005;40: 537-543.

[51] Peña FJ, Saravia F, García-Herreros M, Núñez-Martín I, Tapia JA, Johannisson A, et al. Identification of sperm morphometric subpopulations in two different portions of the boar ejaculate and its relation to postthaw quality. J Androl 2005;26:716-23.

[52] Esteso MC, Fernández-Santos MR, Soler AJ, Montoro V, Martínez-Pastor F, Garde JJ. Identification of sperm head morpho- metric subpopulations in Iberian red deer epididymal sperm samples. Reprod Domest Anim 2008.

[53] Rubio-Guillén J, González D, Garde JJ, Esteso MC, FernándezSantos MR, Rodríguez-Gíl JE, et al. Effects of cryopreservation on bull spermatozoa distribution in morphometrically distinct subpopulations. Reprod Domest Anim 2007;42:354-7.

[54] Martínez-Pastor F, Garcia-Macias V, Alvarez M, Herraez P, Anel L, de Paz P. Sperm subpopulations in Iberian red deer epididymal sperm and their changes through the cryopreservation process. Biol Reprod 2005;72:316-27. 